\title{
Rapid $\mathrm{Ca}^{2+}$-mediated activation of Rap1 in human platelets
}

\author{
Barbara Franke 1,2, Jan-Willem N.Akkerman² \\ and Johannes L.Bos ${ }^{1,3}$ \\ ${ }^{1}$ Laboratory for Physiological Chemistry, Utrecht University, \\ PO Box 80042, 3508 TA Utrecht and ${ }^{2}$ Department of Haematology, \\ University Hospital Utrecht, PO Box 85500, 3508 GA Utrecht, \\ The Netherlands \\ ${ }^{3}$ Corresponding author
}

Rap1 is a small, Ras-like GTPase whose function and regulation are still largely unknown. We have developed a novel assay to monitor the active, GTPbound form of Rap1 based on the differential affinity of Rap1GTP and Rap1GDP for the Rap binding domain of RalGDS (RBD). Stimulation of blood platelets with $\alpha$-thrombin or other platelet activators caused a rapid and strong induction of Rap1 that associated with RBD in vitro. Binding to RBD increased from undetectable levels in resting platelets to $>50 \%$ of total Rap1 within $30 \mathrm{~s}$ after stimulation. An increase in the intracellular $\mathrm{Ca}^{2+}$ concentration is both necessary and sufficient for Rap1 activation since it was induced by agents that increase intracellular $\mathrm{Ca}^{2+}$ and inhibited by a $\mathrm{Ca}^{2+}$-chelating agent. Neither inhibition of translocation of Rap1 to the cytoskeleton nor inhibition of platelet aggregation affected thrombin-induced activation of Rap1. In contrast, prostaglandin $\mathrm{I}_{2}\left(\mathbf{P G I}_{2}\right)$, a strong negative regulator of platelet function, inhibited agonist-induced as well as $\mathrm{Ca}^{2+}$-induced activation of Rap1. From our results, we conclude that Rap1 activation in platelets is an important common event in early agonist-induced signalling, and that this activation is mediated by an increased intracellular $\mathrm{Ca}^{2+}$ concentration.

Keywords: calcium/GTPase/platelet/Rap1/thrombin

\section{Introduction}

Rap1A and Rap1B are two members of the Ras family of small GTPases. Rap1A was first identified both by its homology to Ras and as the product of a cDNA that induces flat revertants of K-ras-transformed cells (Krev-1). Rap1B is a very close relative of Rap1A, differing in only nine amino acids predominantly in the C-terminal part of the protein (Noda, 1993). The functional difference between the two proteins is unclear and in most studies no discrimination between the two has been made. Various functions of Rap1 have been described, some of which are related to the ability of Rap1 to counteract the function of Ras. For instance, introduction of the active, GTPbound form of Rap1 into fibroblasts inhibits Ras-mediated activation of MAP kinase (Cook et al., 1993). In addition, constitutively active Rap1 can inhibit Ras-mediated induction of germinal vesicle breakdown in Xenopus oocytes
(Campa et al.,1991). In vitro Rap1 binds regulators (p120RasGAP; Frech et al., 1990; Hata et al., 1990) and effectors (Raf1, RalGDS; Spaargaren and Bischoff, 1994; Nassar et al., 1995; Wittinghofer and Herrmann, 1995) of Ras, suggesting that the inhibition of Ras function is due to sequestration of Ras effectors by Rap1. Interestingly, cAMP, an inhibitor of Ras signalling in various cell types (Burgering et al., 1993; Cook et al., 1993; Wu et al., 1993), has been reported to induce the activation of exogenously expressed epitope-tagged Rap1 in a Rastransformed fibroblast (Altschuler et al., 1995). However, not all effects of Rap1 point to an inhibition of Ras signalling and indicate that Rap1 has a separate function in various cell types. For instance, in Swiss 3T3 fibroblasts, constitutively active Rap1 induces DNA synthesis (Yoshida et al., 1992). In neutrophils, Rap1 is found in association with the NADPH oxidase system (Quinn et al., 1989), and introduction of Rap1 into neutrophil-like HL60 cells results in a stimulation of this oxidase (Gabig et al., 1995). Also, in blood platelets, Rap1 may play an important role, since Rap1, in particular Rap1B, is highly expressed (Torti and Lapetina, 1994).

Platelets are anuclear cell fragments that adhere to sites of injury in a blood vessel and aggregate to stop bleeding. Adhesion and aggregation are accompanied by a profound change in the morphology of platelets due to remodelling of the actin-based cytoskeleton (Hartwig, 1992; Fox, 1993). Thrombin is the most potent stimulator of platelets, but a large number of other activators has been described (Kroll and Schafer, 1989; Siess, 1989). When platelets are activated, Rap1 is translocated to the platelet cytoskeleton (Fischer et al., 1990, 1994). This translocation is a relatively slow process that depends on aggregation of platelets. In addition, it has been reported that Rap1 associates with p $120^{\text {RasGAP }}$ and PLC $\gamma_{1}$ after platelet stimulation (Torti and Lapetina, 1992). Also, prostaglandin $I_{2}$ $\left(\mathrm{PGI}_{2}\right)$, a strong negative regulator of platelet function, affects Rap1 by inducing the phosphorylation of a serine residue at the C-terminal end of Rap1 (Kawata et al., 1989; Siess et al., 1990). This phosphorylation induces a translocation of Rap1 from the plasma membrane to the cytosol (Lapetina et al., 1989).

Despite all these results, it is still unclear what the function of Rap1 is and in which signal transduction pathway Rap1 is involved. This is partly due to the lack of information on signals that may activate endogenous Rap1, i.e. induce the conversion of the inactive GDPbound form of the protein to the active GTP-bound form. Unfortunately, no antibodies are available that can immunoprecipitate Rap1 to measure the ratio of GTP:GDP bound to Rap1. Therefore, we have developed an alternative, indirect assay to measure Rap1 activation. This assay is based on the differential affinity of Rap1GTP versus Rap1GDP for the Rap binding domain of RalGDS 
(RBD) as shown by Wittinghofer and co-workers (Herrmann et al., 1996): whereas the Rap binding domain of RalGDS binds to the GTP-bound form of Rap1 with a very high affinity $\left(K_{\mathrm{D}}=10 \mathrm{nM}\right)$, the affinity for the GDPbound form is undetectably low. Here we report that in platelets $\alpha$-thrombin stimulation results in a dramatic increase of Rap1 which can associate with RBD in vitro, indicating an increase of Rap1 in the GTP-bound state. We have investigated this activation further and found that most, if not all, activators of platelet function activate Rap1, whereas the negative regulator $\mathrm{PGI}_{2}$ inhibits Rap1 activation. Furthermore, we show that an increase in the intracellular $\mathrm{Ca}^{2+}$ concentration is both necessary and sufficient to activate Rap1. Finally, we show that Rap1 activation occurs independently of, and probably prior to, platelet aggregation and the association of Rap1 with the cytoskeleton. From these results, we conclude that Rap1 is activated rapidly and strongly by $\mathrm{Ca}^{2+}$-mediated signalling after platelet stimulation, suggesting a critical role for Rap1 in platelet activation.

\section{Results}

\section{$\alpha$-Thrombin induces rapid activation of Rap1}

Freshly isolated human platelets were stimulated with $\alpha$-thrombin for various time periods and lysed. Rap1 was precipitated with the polyhistidine-tagged Rap binding domain of RalGDS (RBD) bound to nickel beads and identified by Western blotting using a monoclonal antibody directed against Rap1. This antibody is specific for Rap1, and does not recognize Ras or R-ras (not shown). A rapid and strong increase in the amount of Rap1 that bound to RBD in vitro was observed (Figure 1A). This increase was visible within $5 \mathrm{~s}$ after thrombin addition and reached its maximum level at $\sim 30 \mathrm{~s}$. At this latter time point, $>50 \%$ of total Rap1 could be precipitated with RBD (Figure 1B). Since RBD associates exclusively with the GTP-bound form of Rap1 in vitro, with no detectable affinity for the GDP-bound form of Rap1 (Herrmann et al., 1996), we conclude that $\alpha$-thrombin induces a rapid conversion of the majority of Rap1 to the GTP-bound, active state.

Treatment of platelets with agonists other than $\alpha$-thrombin (Benton et al., 1982; Kroll and Schafer, 1989; Siess, 1989; Inazu et al., 1991) also caused activation of Rap1; the thrombin receptor-activating peptide (TRAP), collagen, the thromboxane $\mathrm{A}_{2}\left(\mathrm{TxA}_{2}\right)$ analogue U46619, ADP and platelet-activating factor (PAF) all induced rapid and strong Rap1 activation (Figure 2). Wheat germ agglutinin and lysophosphatidic acid (LPA) treatment also resulted in Rap1 activation (data not shown). From these results, we conclude that Rap1 is activated rapidly and strongly by signalling events common to most, if not all platelet agonists.

\section{Rap1 activation occurs independently of secretion and platelet aggregation}

During thrombin-induced platelet activation, $\mathrm{TxA}_{2}$ and $\mathrm{ADP}$ are released by platelets. Both act in positive feedback loops to enhance further the ongoing platelet activation (Kroll and Schafer, 1989; Siess, 1989). As TxA 2 and ADP induce Rap1 activation, we investigated whether thrombininduced Rap1 activation is a consequence of these pro-
A

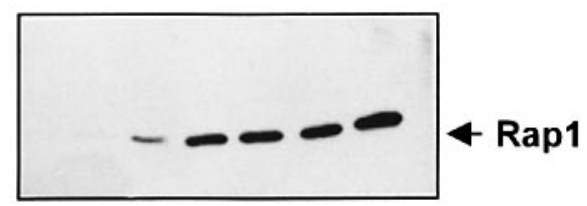

$\begin{array}{llllllll}0 & 1 & 5 & 10 & 20 & 30 & 60 & \text { time (sec) }\end{array}$

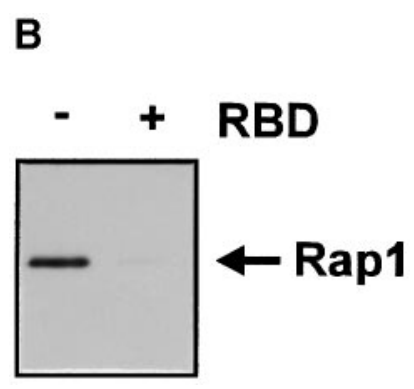

Fig. 1. $\alpha$-Thrombin stimulation of blood platelets results in increased binding of Rap1 to RBD in vitro. (A) Platelets were stimulated with $0.25 \mathrm{U} / \mathrm{ml} \alpha$-thrombin for the indicated time periods and lysed. Rap1 was precipitated with his-tagged $\mathrm{RBD}$ bound to $\mathrm{Ni}^{2+}-\mathrm{NTA}$-agarose beads, and identified with a monoclonal antibody directed against Rap1 after SDS-PAGE and Western blotting. (B) Platelet lysate was incubated with either $\mathrm{Ni}^{2+}$-NTA-agarose beads (-) or his-tagged RBD bound to $\mathrm{Ni}^{2+}$-NTA-agarose beads $(+)$. After removal of the beads, the supernatant was separated by SDS-PAGE, and Rap1 was detected by immunoblotting with a Rap1-specific monoclonal antibody.

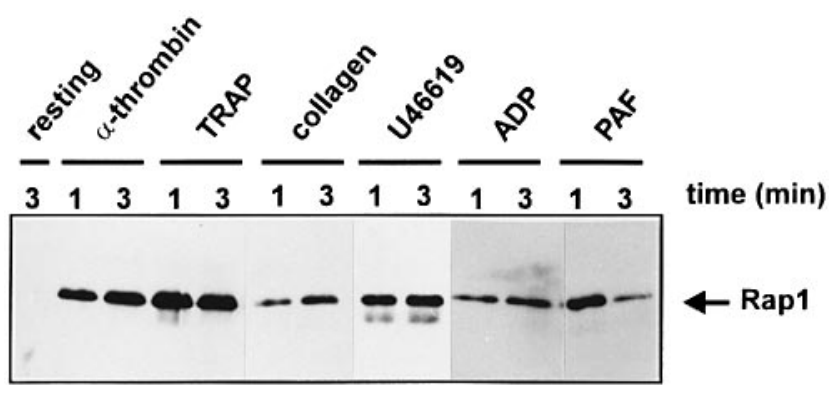

Fig. 2. Rap1 activation is induced by different platelet agonists Platelets were stimulated for 1 and $3 \mathrm{~min}$ with $\alpha$-thrombin $(0.1 \mathrm{U} / \mathrm{ml})$, TRAP $(10 \mu \mathrm{M})$, collagen $(5 \mu \mathrm{g} / \mathrm{ml})$, the thromboxane $\mathrm{A}_{2}$ analogue U46619 $(1 \mu \mathrm{M}), \operatorname{ADP}(10 \mu \mathrm{M})$ and PAF $(200 \mathrm{nM})$. Resting platelets were treated with buffer for $3 \mathrm{~min}$. Rap1 was isolated and identified as indicated in the legend to Figure 1.

cesses. Treatment of platelets with indomethacin inhibits $\mathrm{TxA}_{2}$ formation (Shen and Winter, 1977); addition of phosphoenolpyruvate and pyruvate kinase (PEP:PK) scavenges ADP, thus inhibiting ADP signalling (Ammit and O'Neill, 1991; Van Willigen et al., 1996). Addition of both inhibitors together, at concentrations causing complete inhibition of both pathways, resulted in only a partial inhibition of Rap1 activation (Figure 3). From these results, we conclude that although both $\mathrm{TxA}_{2}$ and ADP do contribute to thrombin-induced activation of Rap1, they are not essential for thrombin to induce Rap1.

Previously, it was shown that Rap1 translocates to the platelet cytoskeleton in a mainly aggregation-dependent manner (Fischer et al., 1994). We therefore investigated the effects of disruption of the cytoskeleton and inhibition of platelet aggregation on thrombin-induced Rap1 activ- 


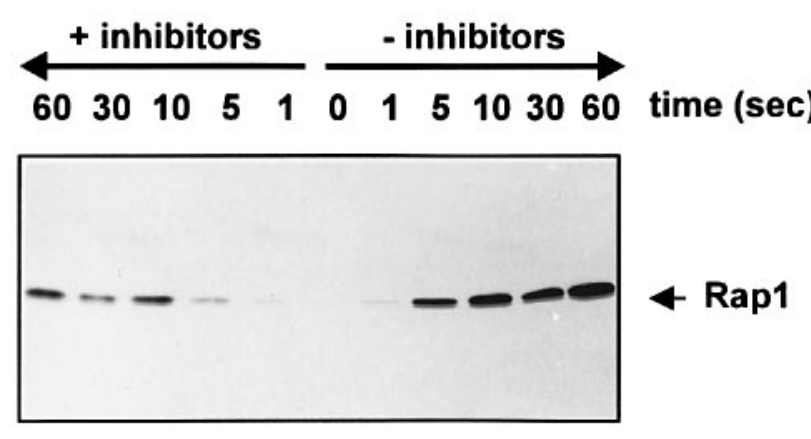

Fig. 3. Rap1 activation occurs independently of both $\mathrm{Tx} \mathrm{A}_{2}$ formation and ADP secretion. In the lanes marked ' + inhibitors' platelets were incubated with $30 \mu \mathrm{M}$ indomethacin for $10 \mathrm{~min}$ to inhibit $\mathrm{TxA}_{2}$ formation. In the last minute, the ADP scavenger system phosphoenolpyruvate:pyruvate kinase (PEP:PK) was added at a final concentration of $0.28 \mathrm{mM}$ PEP and $3 \mathrm{U} / \mathrm{ml}$ PK. Subsequently, the platelets were incubated with $0.1 \mathrm{U} / \mathrm{ml} \alpha$-thrombin for the indicated time periods, and Rap1 was isolated and detected as indicated in the legend to Figure 1. Control platelets (- inhibitors) were treated with $0.1 \mathrm{U} / \mathrm{ml} \alpha$-thrombin, only.

ation. Treatment of platelets with cytochalasin D prevents activation-dependent actin polymerization and remodelling of the cytoskeleton (Dash et al., 1995). This treatment totally prevented the translocation of Rap1 to the cytoskeleton (Figure 4A). Cytochalasin D, however, did not affect thrombin-induced activation of Rap1 (Figure 4B), showing that Rap1 activation occurs independently of translocation to the cytoskeleton. Furthermore, in platelets that were not allowed to aggregate by the addition of the RGDS peptide, which blocks integrin function (Hynes, 1992; Calvete, 1994), Rap1 activation was not impaired (Figure 5). Also, inhibition of aggregation by not stirring the platelet suspension did not affect $\alpha$-thrombin-induced activation of Rap1 (data not shown). From these results, we conclude that Rap1 activation occurs independently of Rap1 translocation to the cytoskeleton and of platelet aggregation.

\section{Increase in intracellular $\mathrm{Ca}^{2+}$ is necessary and sufficient for Rap1 activation}

One of the signalling events shared by platelet agonists is the activation of phospholipase $\mathrm{C}$ (PLC), which releases diacylglycerol (DAG) to activate protein kinase $\mathrm{C}$ (PKC), and inositol-1,4,5-triphosphate $\left(\mathrm{InsP}_{3}\right)$ to mobilize $\mathrm{Ca}^{2+}$ from intracellular stores (Kroll and Schafer, 1989; Siess, 1989). Figure 6A demonstrates that inhibition of PLC by U73122 (Okamoto et al., 1995) strongly reduced thrombininduced activation of Rap1, suggesting that either PKC or $\mathrm{Ca}^{2+}$ is an important factor in Rap1 regulation. We therefore tested whether an increase in the intracellular $\mathrm{Ca}^{2+}$ concentration is important for the activation of Rap1. Inhibition of the cytosolic $\mathrm{Ca}^{2+}$ increase by chelation of intracellular $\mathrm{Ca}^{2+}$ with BAPTA-AM (Watson et al., 1995) completely blocked activation of Rap 1 by $\alpha$-thrombin. On the other hand, increasing the concentration of intracellular $\mathrm{Ca}^{2+}$ with ionomycin (Cavallini and Alexandre, 1994; Doni et al., 1994) or thapsigargin (Authi et al., 1993; Cavallini et al., 1995) strongly activated Rap1 (Figure $6 \mathrm{~A})$. This indicates that an increased level of $\mathrm{Ca}^{2+}$ is both necessary and sufficient to activate Rap1. The $\mathrm{Ca}^{2+}$ effect is not due simply to $\mathrm{Ca}^{2+}$-induced production and release
A
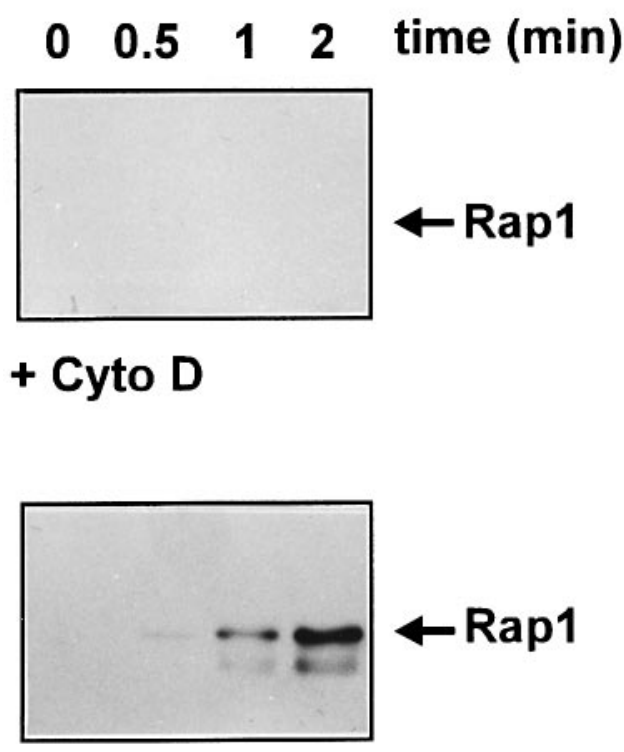

B

$\begin{array}{lllll}0 & 0.5 & 1 & 2 & \text { time }(\mathrm{min})\end{array}$
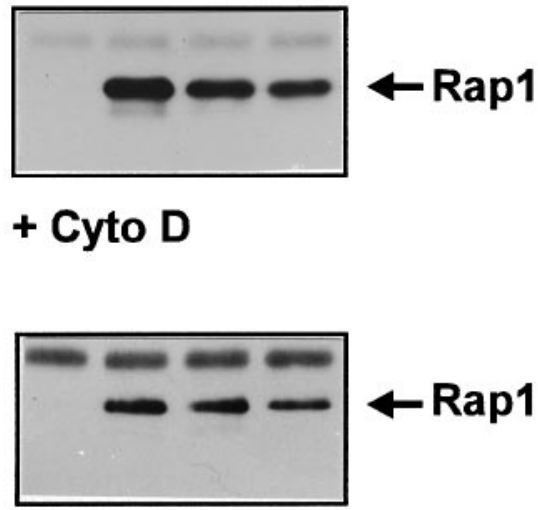

Fig. 4. Inhibition of actin polymerization prevents Rap1 translocation but does not affect thrombin-induced activation of Rap1. Platelets were treated with cytochalasin D (Cyto D, $5 \mu \mathrm{g} / \mathrm{ml}$ ) (top) or DMSO (bottom) $5 \mathrm{~min}$ prior to stimulation with $0.2 \mathrm{U} / \mathrm{ml} \alpha$-thrombin for the indicated time periods under aggregating conditions (stirring).

(A) Cytoskeletal proteins were isolated as described in Materials and methods. Amounts of protein representing $3 \times 10^{7}$ platelets were used for protein immunoblot analysis with a monoclonal antibody directed against Rap1. (B) Rap1 was precipitated with RBD and analysed as indicated in the legend of Figure 1. The band present above Rap1 is caused by aspecific binding to the $\mathrm{Ni}^{2+}$-NTA-agarose beads.

of $\mathrm{TxA}_{2}$ or secretion of ADP, since inhibitors of both signalling events, indomethacin and PEP:PK, caused only a slight reduction of $\mathrm{Ca}^{2+}$-induced Rap1 activation (Figure 6A). Moreover, this reduction is probably due to the slightly lower $\mathrm{Ca}^{2+}$ level induced by thapsigargin and ionomycin in the presence of indomethacin and PEP:PK (data not shown).

Inhibition of PKC by several inhibitors, i.e. staurosporin, bisindolylmaleimid and calphostin C (Tamaoki, 1991; Toullec et al., 1991), did not at all or only marginally affect the activation of Rap1 by $\alpha$-thrombin (Figure 6B). Consistent with this, activation of PKC by the phorbol 


\section{$\begin{array}{lllll}0 & 0.5 & 1 & 2 & \text { time }(\mathrm{min})\end{array}$}
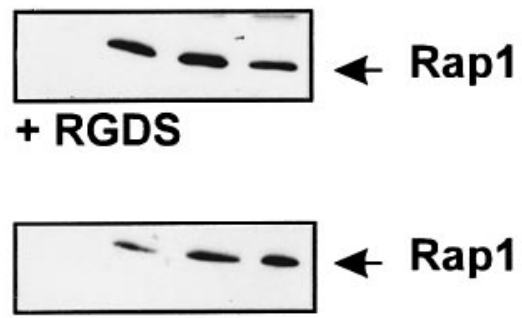

Fig. 5. Inhibition of platelet aggregation does not affect thrombininduced activation of Rap1. Platelets were treated with $0.1 \mathrm{U} / \mathrm{ml}$ $\alpha$-thrombin under aggregating conditions for the indicated time periods in the presence (+RGDS) or absence of $100 \mu \mathrm{M}$ of the aggregationinhibitory peptide RGDS added 1 min prior to activation. Rap1 was precipitated with RBD and analysed as indicated in the legend to Figure 1.

ester phorbol 12-myristate 13-acetate (PMA) (Kroll and Schafer, 1989; Siess, 1989) activated Rap1 only slightly and after a prolonged period of time (Figure 6B). From these results, we conclude that Rap1 activation is mediated by an increase in intracellular $\mathrm{Ca}^{2+}$, which is both necessary and sufficient, whereas activation of PKC does not play an essential role.

\section{Prostaglandin $I_{2}\left(P G I_{2}\right)$ inhibits thrombin- and $\mathrm{Ca}^{2+}$-induced Rap1 activation}

$\mathrm{PGI}_{2}$, a potent inducer of cAMP production, is a strong antagonist of platelet activation (Kroll and Schafer, 1989; Siess, 1989). We therefore tested the effect of $\mathrm{PGI}_{2}$ on thrombin-induced activation of Rap1. Figure 7A shows that addition of $\mathrm{PGI}_{2}$ inhibited thrombin-induced activation of Rap1 completely. Furthermore, when platelets were first treated with thrombin and subsequently with $\mathrm{PGI}_{2}$, the initial activation of Rap1 was followed by a rapid down-regulation (Figure 7B). Interestingly, the activity of Rap1 (again) correlated with the level of intracellular $\mathrm{Ca}^{2+}$ (Figure 7C). However, $\mathrm{Ca}^{2+}$-induced activation of Rap1 by thapsigargin and ionomycin was also fully blocked by $\mathrm{PGI}_{2}$ (Figure 7D), even though the intracellular $\mathrm{Ca}^{2+}$ levels induced by thapsigargin or ionomycin were still high in the presence of $\mathrm{PGI}_{2}$ (data not shown; Siess and Lapetina, 1989; Nakamura et al., 1995). These results show that Rap1 activity is under tight negative control of $\mathrm{PGI}_{2}$, which acts both upstream and downstream of $\mathrm{Ca}^{2+}$.

$\mathrm{PGI}_{2}$ activates adenylate cyclase resulting in an increase in the cAMP level. It is intriguing that Rap1 is an in vivo substrate for cAMP-dependent protein kinase A (PKA) (Kawata et al., 1989; Siess et al., 1990). This phosphorylation, which results in a lower electrophoretic mobility of Rap1 (Siess et al., 1990; Siess and Grünberg, 1993), occurs only slowly and was still very limited 2 min after $\mathrm{PGI}_{2}$ treatment of the platelets (Figure 8A; Grünberg et al., 1995). At this time point, however, $\mathrm{PGI}_{2}$ had already completely inhibited Rap1 activity (see Figure 7A). Furthermore, $\alpha$-thrombin was able to activate phosphorylated Rap1 apparently normally. This was shown by pre-treating platelets with $\mathrm{PGI}_{2}$ for various times, followed by thrombin stimulation: whereas platelets became fully responsive to thrombin stimulation within 60 min after $\mathrm{PGI}_{2}$ addition (due to the instability of $\mathrm{PGI}_{2}$ ), Rap1 phosphorylation remained high (Figure 8A; Siess and Grünberg, 1993;
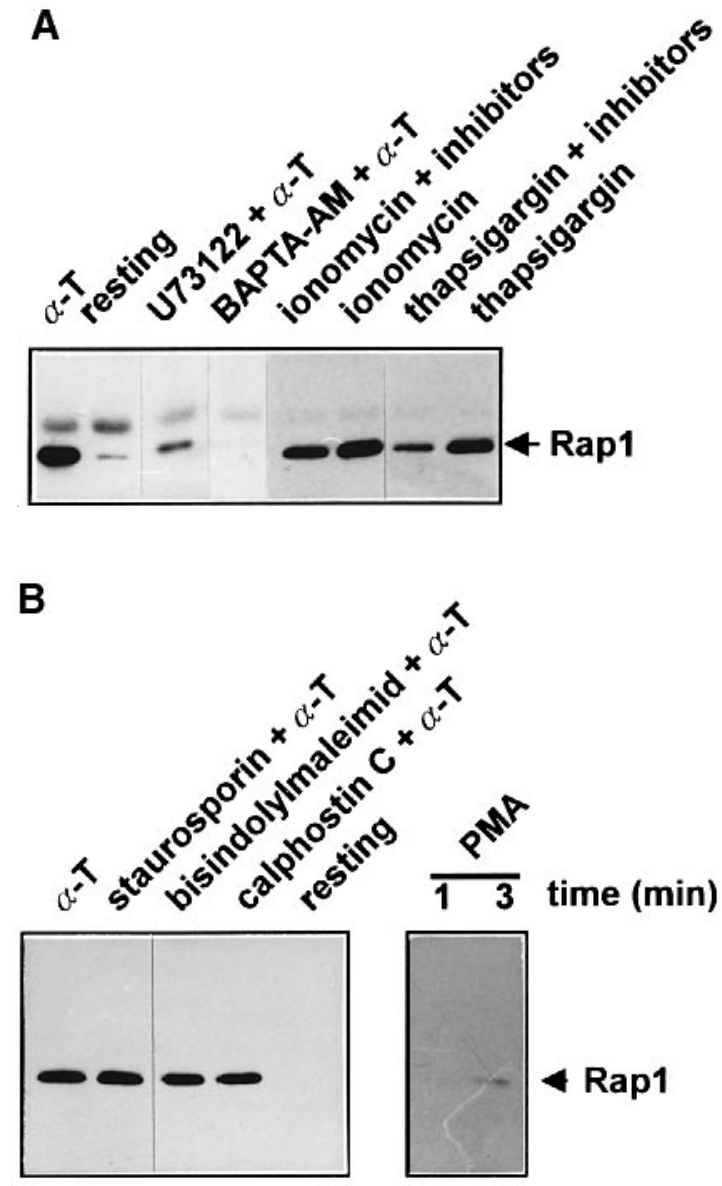

Fig. 6. Role of PLC, $\mathrm{Ca}^{2+}$ and PKC in $\alpha$-thrombin-induced Rap activation. (A) U73122 and BAPTA-AM inhibit Rap1 activation, whereas ionomycin and thapsigargin stimulate it. Platelets were incubated with either the PLC inhibitor U73122 (1 $\mu \mathrm{M}, 3 \mathrm{~min})$ or the intracellular $\mathrm{Ca}^{2+}$ chelator BAPTA-AM $(30 \mu \mathrm{M}, 30 \mathrm{~min})$ prior to $1 \mathrm{~min}$ of thrombin $(0.1 \mathrm{U} / \mathrm{ml})$ stimulation. In addition, platelets were activated in the absence of thrombin with either ionomycin $(100 \mathrm{nM})+\mathrm{CaCl}_{2}(1 \mathrm{mM})$ or thapsigargin $(100 \mathrm{nM})$, both for $1 \mathrm{~min}$. In the lanes labelled 'ionomycin + inhibitors' and 'thapsigargin + inhibitors' platelets were pre-treated with inhibitors of Tx $\mathrm{A}_{2}$ production and ADP signalling (as indicated in the legend to Figure 2) prior to $1 \mathrm{~min}$ of treatment with either ionomycin $+\mathrm{CaCl}_{2}$ or thapsigargin. Rap1 was precipitated with RBD and analysed as indicated in the legend to Figure 1. The band present above Rap1 on the blot is caused by aspecific binding of protein to the $\mathrm{Ni}^{2+}-\mathrm{NTA}-$ agarose beads. (B) Inhibition or activation of PKC do not significantly affect Rap1 activity. Platelets were incubated with the PKC inhibitors staurosporin ( $1 \mu \mathrm{M}, 5 \mathrm{~min})$, bisindolylmaleimid ( $5 \mu \mathrm{M}, 1 \mathrm{~min})$, calphostin $\mathrm{C}(5 \mu \mathrm{M}, 5 \mathrm{~min})$ prior to a $1 \mathrm{~min}$ thrombin stimulation $(0.1 \mathrm{U} / \mathrm{ml})$ (left panel). In the right panel, platelets were stimulated with the PKC-activating phorbol ester PMA (10 nM) for 1 and $3 \mathrm{~min}$. Rap1 was precipitated with RBD and analysed as indicated in the legend to Figure 1.

Grünberg et al., 1995). Under these conditions, thrombin activated the phosphorylated, shifted form of Rap1 (Figure $8 \mathrm{~B})$. We conclude, therefore, that the $\mathrm{PGI}_{2}$-induced inhibition of Rap1 activation is not caused by phosphorylation of the GTPase.

\section{Discussion}

We have developed a novel assay to identify the active GTP-bound state of Rap1. This assay is based on the observation that the GTP-bound form of Rap1 associates 
with the RBD of RalGDS with high affinity in vitro, whereas no interaction can be detected with the GDPbound form of Rap1. When we incubated cell lysates of resting and $\alpha$-thrombin-stimulated human blood platelets

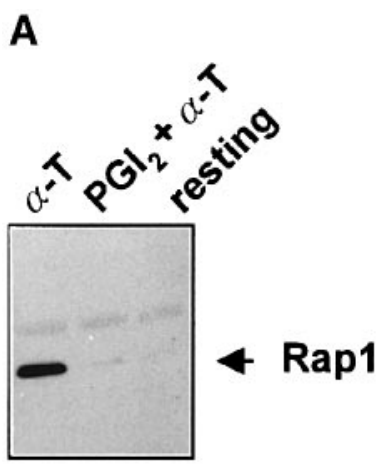

B

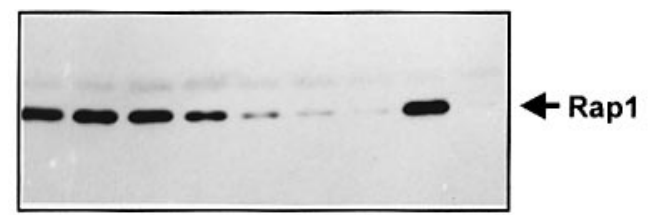

$151515151515151200 \quad \alpha$-thrombin (sec)

$\begin{array}{llllllllll}0 & 1 & 5 & 15 & 30 & 60 & 105 & 0 & 0 & \mathrm{PGI}_{2} \text { (sec) }\end{array}$ C

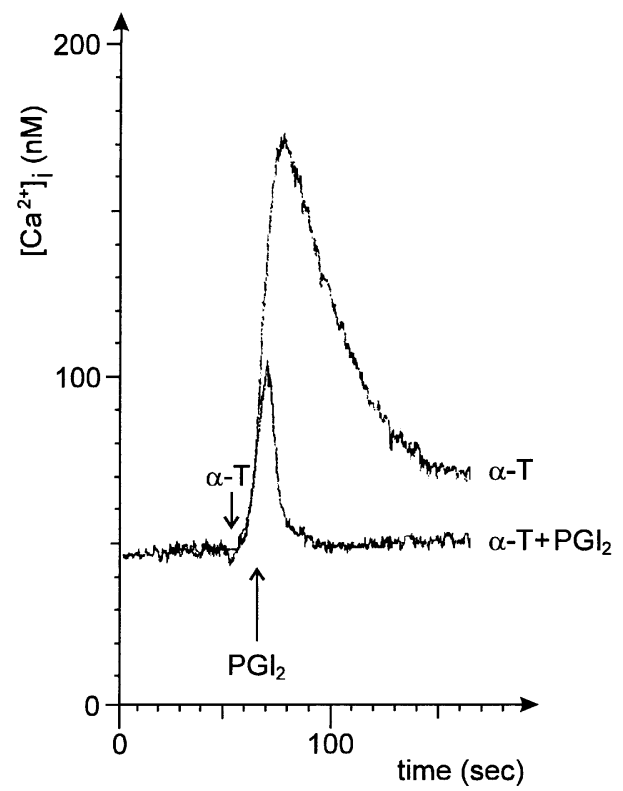

D

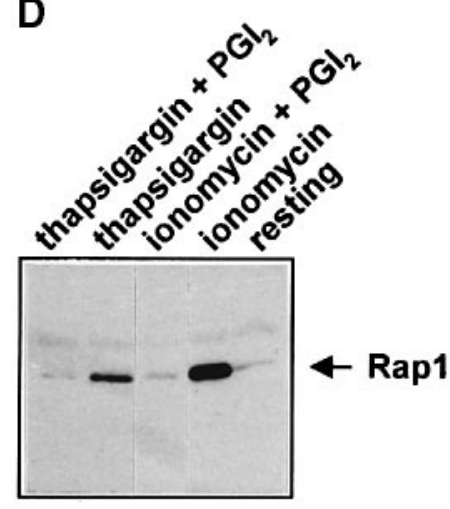

with polyhistidine-tagged $\mathrm{RBD}$ bound to $\mathrm{Ni}^{2+}-\mathrm{NTA}-$ agarose beads, we observed a large amount of Rap1 associated with RBD only in stimulated platelets. Based on the in vitro binding affinity, we conclude that this increase is due to an induction of the GTP-bound form of Rap1 by $\alpha$-thrombin. Alternatively, Rap 1 might be constitutively GTP-bound but complexed to a factor in resting platelets that prevents it from associating with RBD. Stimulation with thrombin would then lead to dissociation of this factor, rendering Rap1 available for RBD binding. To discriminate between the two possibilities, the ratio of GDP and GTP bound to Rap1 in platelets needs to be measured. Unfortunately, suitable antisera for Rap1 immunoprecipitation, which are essential for such an experiment, are still not available. Irrespective of this, in functional terms there may be no difference between the two mechanisms, as both result in free GTPbound, active Rap1.

The assay was used to monitor the activation of Rap1 in platelets. We observed that all agonists tested that activate platelets also activate Rap1. This could imply that Rap1 is either involved in a signalling pathway common to all of these agonists or that Rap1 activation is a secondary event, induced by positive feedback loops $\left(\mathrm{Tx}_{2}\right.$ release and ADP secretion) or by platelet aggregation, for instance. However, inhibition of both $\mathrm{TxA}_{2}$ production and ADP signalling as well as aggregation did not affect $\alpha$-thrombin-induced activation of Rap1 significantly. This strongly suggests that Rap1 activation is one of the early events in platelet activation. The observed translocation of Rap1 to the cytoskeleton is not involved in the activation of Rap1, since it occurs much later than Rap1 activation. Furthermore, inhibition of actin polymerization by cytochalasin D, which totally blocked Rap1 association with the cytoskeleton, did not inhibit Rap1 activation. Therefore, we conclude that Rap1 is involved in a signalling pathway common to all agonists tested. A common denominator for all these agonists is the increase in intracellular $\mathrm{Ca}^{2+}$ by mobilization of $\mathrm{Ca}^{2+}$ from internal stores and by influx of extracellular $\mathrm{Ca}^{2+}$. Indeed, we found that increasing the concentration of intracellular $\mathrm{Ca}^{2+}$ with either ionomycin or thapsigargin induced Rap1

Fig. 7. Effects of $\mathrm{PGI}_{2}$ treatment of platelets on Rap1 activation and cytosolic $\mathrm{Ca}^{2+}$ levels. (A) $\mathrm{PGI}_{2}$ pre-treatment prevents Rap1 activation by $\alpha$-thrombin. Platelets were treated with thrombin $(\alpha-T, 0.1 \mathrm{U} / \mathrm{ml})$, in the presence or absence of $\mathrm{PGI}_{2}$ added 2 min earlier at $10 \mathrm{ng} / \mathrm{ml}$. Rap1 was precipitated with RBD and analysed as indicated in the legend to Figure 1. (B) $\mathrm{PGI}_{2}$ treatment of $\alpha$-thrombin-activated platelets results in a time-dependent reduction of Rap1 activity. Platelets were treated with $\alpha$-thrombin $(0.1 \mathrm{U} / \mathrm{ml})$ for $15 \mathrm{~s}$ to activate Rap1. $\mathrm{PGI}_{2}(10 \mathrm{ng} / \mathrm{ml})$ was then added for the indicated times. Controls were either left untreated or were activated with $\alpha$-thrombin for $120 \mathrm{~s}$ to serve as a positive control for the activity state of Rap1 at the end of the experiment. Rap1 was precipitated with RBD and analysed as indicated in the legend to Figure 1. (C) $\mathrm{PGI}_{2}$ reverses the $\alpha$-thrombin-induced rise in the cytosolic $\mathrm{Ca}^{2+}$ level. The intracellular $\mathrm{Ca}^{2+}$ level was monitored in Fura-2-loaded platelets as described in Materials and methods. $\alpha$-Thrombin $(0.1 \mathrm{U} / \mathrm{ml})$ was added at the indicated time point $(\alpha-\mathrm{T}), 15 \mathrm{~s}$ later $\mathrm{PGI}_{2}(10 \mathrm{ng} / \mathrm{ml})$ was added (indicated with $\mathrm{PGI}_{2}$ ) and incubation was continued for another $90 \mathrm{~s}$. (D) $\mathrm{PGI}_{2}$ pre-treatment of platelets prevents Rap1 activation by the cytosolic $\mathrm{Ca}^{2+}$-elevating agents thapsigargin and ionomycin. Platelets were incubated either with or without $\mathrm{PGI}_{2}(10 \mathrm{ng} / \mathrm{ml})$ for $2 \mathrm{~min}$. Subsequently, either ionomycin $(100 \mathrm{nM})+\mathrm{CaCl}_{2}(1 \mathrm{mM})$ or thapsigargin $(100 \mathrm{nM})$ was added for 1 min. Rap1 was precipitated with RBD and analysed as indicated in the legend to Figure 1. 
A

$0260120150180 \quad$ time (min)

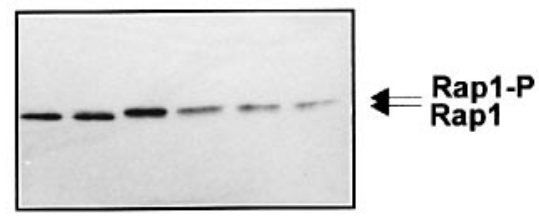

B
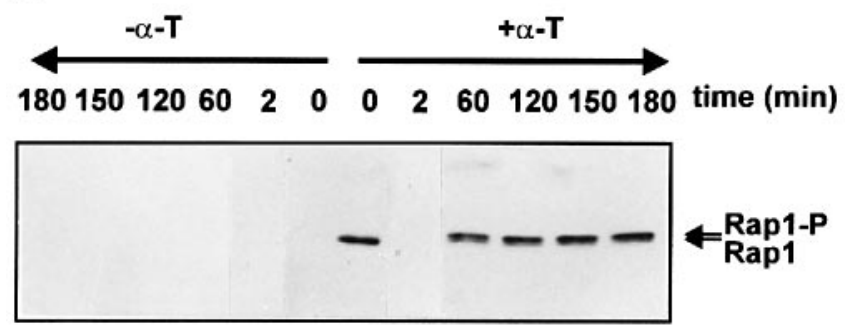

Fig. 8. $\mathrm{PGI}_{2}$-induced phosphorylation of Rap1 does not affect Rap1 activation. (A) $\mathrm{PGI}_{2}$ induces a mobility shift of Rap1. Total lysates of platelets treated with $\mathrm{PGI}_{2}(20 \mathrm{ng} / \mathrm{ml})$ for the indicated time periods were separated and analysed by protein immunoblot analysis for the presence of phosphorylated Rap1. The phosphorylated form of Rap1 shows decreased electrophoretic mobility during SDS-PAGE and can therefore be detected as a second Rap1 band on the immunoblot, indicated by Rap1-P. (B) $\alpha$-Thrombin induces activation of phosphorylated Rap1. Platelets were treated with $\mathrm{PGI}_{2}(20 \mathrm{ng} / \mathrm{ml})$ for the indicated time periods. Subsequently, thrombin was added and the incubation was continued for another minute, followed by cell lysis $(+\alpha-\mathrm{T})$. As a control, platelets incubated with $\mathrm{PGI}_{2}$ were not incubated with thrombin $(-\alpha-T)$. Rap1 was precipitated with RBD and analysed as indicated in the legend to Figure 1. Rap1-P indicates the slower migrating, phosphorylated form of Rap1. It should be noted that due to the instability of $\mathrm{PGI}_{2}$ its inhibitory effect on Rap1 activation by $\alpha$-thrombin is only seen 2 min after $\mathrm{PGI}_{2}$ addition to the platelets. At all later time points, $\mathrm{PGI}_{2}$ has been broken down and platelets have restored responsiveness to $\alpha$-thrombin (Siess and Lapetina, 1990; Siess and Grünberg, 1993).

activation. In addition, BAPTA-AM, which chelates intracellular $\mathrm{Ca}^{2+}$, inhibited thrombin-induced Rap1 activation. Apparently, Rap1 activation is mediated by a rise in intracellular $\mathrm{Ca}^{2+}$. The mechanism by which the $\mathrm{Ca}^{2+}$ increase results in Rapl activation, however, is unclear and currently under investigation.

$\mathrm{PGI}_{2}$, which activates adenylate cyclase to increase the levels of cAMP in platelets, inhibits thrombin-induced activation of Rap1. This is in agreement with the observation that $\mathrm{PGI}_{2}$ inhibited thrombin-induced increases in intracellular $\mathrm{Ca}^{2+}$. However, thapsigargin- or ionomycininduced activation of Rap1 was also inhibited by $\mathrm{PGI}_{2}$, indicating that the antagonist also affects a factor downstream of $\mathrm{Ca}^{2+}$. Although Rap1 is phosphorylated after $\mathrm{PGI}_{2}$ treatment of platelets, it is unlikely that this phosphorylation causes the inhibition. We conclude this from the observation that (i) $\mathrm{PGI}_{2}$-induced phosphorylation of Rap1 was a much later event than inhibition of Rap1, and (ii) thrombin could activate the phosphorylated form of Rap1. It should be noted here that the detection of the phosphorylated form of Rap1 by a mobility shift is an accurate method, as it has been shown by others that $\mathrm{PGI}_{2}$-induced phosphorylation invariantly is accompanied by the shift in mobility (Siess et al., 1990). Another candidate for mediating the $\mathrm{PGI}_{2}$ inhibition is Rap1GAP. Phosphorylation of this protein is induced by elevated levels of cAMP, at least in insect cells and the SK-MEL-3 cell line (Polakis et al., 1992; Rubinfeld et al., 1992). Whether this occurs in platelets and whether it affects GAP activity is still unknown. It should be noted that phosphorylation of Rap1 correlates with the $\mathrm{PGI}_{2}$-induced translocation of Rap1 from the plasma membrane to the cytosol (Lapetina et al., 1989). This translocation may be another form of inactivation by $\mathrm{PGI}_{2}$, which clearly interferes at a different level of Rap1-mediated signalling.

From the rapid activation of a major fraction of Rap1 and the stringent control of Rap1 activity by $\mathrm{PGI}_{2}$, we anticipate that Rap1 plays a critical role in agonistinduced, calcium-mediated events in platelet activation. Interestingly, $\mathrm{Ca}^{2+}$-induced signalling is involved in the activation of integrin $\alpha \operatorname{IIb} \beta 3$, resulting in the exposure of binding sites for fibrinogen and, subsequently, platelet aggregation (Kroll and Schafer, 1989; Siess, 1989). It is tempting, therefore, to speculate that Rap1 is involved in this process. Support for this possibility comes from the recent finding that $\mathrm{R}$-ras, a close relative of Rap1, is involved in the activation of integrins in various cell lines (Zhang et al., 1996). A function of Rap1 in the activation of integrins is not incompatible with the flat revertant phenotype of Krev-1/Rap1 in transformed fibroblasts.

\section{Materials and methods}

\section{Production of his-tagged RaIGDS-RBD}

The cDNA encoding the 97 amino acids spanning RBD was isolated from pGEX-RGF97 (Herrmann et al., 1996) as a BamHI-XhoI fragment. The BamHI site was blunted with Klenow DNA polymerase. Subsequently, the fragment was inserted into the pET-15b vector (Novagen) digested with NdeI (and blunted with Klenow DNA polymerase) and XhoI. The construct was transformed into Escherichia coli (strain BL21). Protein production was initiated by addition of isopropyl $\beta$-Dthiogalactopyranoside (IPTG) to the culture. The fusion protein was affinity purified on a $\mathrm{Ni}^{2+}$-NTA-agarose column (Qiagen) from the supernatant of bacteria lysed by sonication and freeze-thaw cycles in a sucrose-containing buffer.

\section{Isolation and stimulation of platelets}

Freshly drawn venous blood from healthy volunteers (with informed consent) was collected into trisodium citrate $(0.1$ vol. of $130 \mathrm{mM}$ trisodium citrate). The donors claimed not to have taken any medication during the previous 10 days. The blood was centrifuged at $200 \mathrm{~g}$ for $15 \mathrm{~min}$ at room temperature to yield platelet-rich plasma (PRP). Then, 0.1 vol. of ACD (2.5\% trisodium citrate, $1.5 \%$ citric acid, $2 \%$ D-glucose) was added to the PRP to lower the $\mathrm{pH}$ of the plasma to 6.5 and thus prevent platelet activation during further isolation. Platelets were purified from PRP by centrifugation at 700 $g$ for $15 \mathrm{~min}$ at room temperature. The platelet pellet was resuspended in HEPES/Tyrode buffer (10 mM HEPES, $137 \mathrm{mM} \mathrm{NaCl}, 2.68 \mathrm{mM}$ $\mathrm{KCl}, 0.42 \mathrm{mM} \mathrm{NaH} \mathrm{PO}_{4}, 1.7 \mathrm{mM} \mathrm{MgCl}, 11.9 \mathrm{mM} \mathrm{NaHCO} 3, \mathrm{pH}$ 7.4) containing $5 \mathrm{mM}$ D-glucose at $2 \times 10^{8}$ platelets $/ \mathrm{ml}$. Platelets were left at room temperature for at least $30 \mathrm{~min}$ to ensure a resting state. Samples of $0.5 \mathrm{ml}$ were used for the experiments. Purified platelets were incubated in a lumiaggregometer (CHRONO-LOG corporation) at $37^{\circ} \mathrm{C}$. In the standard assay, incubation with agonists was without stirring. Without stirring, platelets only change their shape but do not aggregate, whereas in a stirred suspension (900 r.p.m.) platelet shape change and aggregation occur. Platelet agonists used in the study are: $\alpha$-thrombin which was added to the platelets for $1 \mathrm{~min}$ at a final concentration of $0.1,0.2$ or $0.25 \mathrm{U} / \mathrm{ml}$ (as indicated), TRAP (6mer: SFLLRN) $(10 \mu \mathrm{M})$, collagen $(5 \mu \mathrm{g} / \mathrm{ml})$, U46619 $\left(\mathrm{TxA}_{2}\right.$ analogue) $(1 \mu \mathrm{M})$, ADP $(10 \mu \mathrm{M})$ and PAF $(200 \mathrm{nM})$. PMA was added to the platelets at a final concentration of $10 \mathrm{nM}$, thapsigargin, an inhibitor of intracellular $\mathrm{Ca}^{2+}$ ATPases, was used at $100 \mathrm{nM}$ concentration as was ionomycin, a $\mathrm{Ca}^{2+}$ ionophore. In the 
case of ionomycin, $1 \mathrm{mM} \mathrm{CaCl}_{2}$ was added to the platelet suspension just prior to stimulation. $\mathrm{PGI}_{2}$ was used at a concentration of 10 or $20 \mathrm{ng} / \mathrm{ml}$ and incubated with the platelets for $2 \mathrm{~min}$ (unless indicated otherwise). The PLC inhibitor U73122 (1 $\mu \mathrm{M})$ was present during 3 min pre-incubation. The inactive component U73343 used as control had no effect on Rap1 activity (data not shown). BAPTA-AM (30 $\mu \mathrm{M})$, an intracellular $\mathrm{Ca}^{2+}$ chelator, was pre-incubated with the platelet suspension for $30 \mathrm{~min}$. Indomethacin $(30 \mu \mathrm{M})$ was added to the platelets for $10 \mathrm{~min}$ to inhibit $\mathrm{TxA}_{2}$ formation. The ADP scavenger PEP:PK was freshly prepared prior to every experiment and added to the platelets at a final concentration of $0.28 \mathrm{mM}$ PEP and $3 \mathrm{U} /$ $\mathrm{ml} \mathrm{PK} 1 \mathrm{~min}$ before stimulation. PKC inhibitors were used as follows: staurosporin $(1 \mu \mathrm{M}), 5 \mathrm{~min}$ incubation, bisindolylmaleimid $(5 \mu \mathrm{M})$, 1 min incubation, calphostin $\mathrm{C}(5 \mu \mathrm{M}), 5$ min incubation. Cytochalasin $\mathrm{D}$ was added to the platelet suspension at a concentration of $5 \mu \mathrm{g}$ / $\mathrm{ml} 5 \mathrm{~min}$ prior to platelet stimulation. The peptide RGDS was used at a concentration of $100 \mu \mathrm{M}$ and was added to the platelets $1 \mathrm{~min}$ prior to stimulation. RGDS binds to the ligand binding site of the platelet integrin $\alpha \operatorname{Ilb} \beta 3$. It inhibits binding of fibrinogen to the integrin and therefore blocks platelet aggregation. RGDS does not activate outside-in signalling of integrin $\alpha \operatorname{IIb} \beta 3$ (Hynes, 1992; Calvete, 1994).

\section{Rap1 activation assay using RaIGDS-RBD}

Platelets were lysed by addition of 1 vol. of cold $2 \times$ RIPA lysis buffer $[150 \mathrm{mM} \mathrm{NaCl}, 100 \mathrm{mM}$ Tris- $\mathrm{HCl} \mathrm{pH} 7.4,2 \% \mathrm{NP}-40,1 \%$ deoxycholic acid (DOC), $0.2 \%$ SDS, $2 \mathrm{mM}$ sodium orthovanadate, 2 $\mathrm{mM}$ phenylmethylsulfonyl fluoride (PMSF), $2 \mu \mathrm{M}$ leupeptin, $2 \mu \mathrm{M}$ aprotinin] to the platelet suspension. Lysis was performed at $4{ }^{\circ} \mathrm{C}$ for 10-30 min. Lysates were clarified by centrifugation at maximal speed in an Eppendorf centrifuge for $10 \mathrm{~min}$ at $4^{\circ} \mathrm{C}$. Five $\mu \mathrm{g}$ of RalGDSRBD coupled to $\mathrm{Ni}^{2+}$-NTA-agarose beads (Qiagen) were added to the supernatant and incubated at $4^{\circ} \mathrm{C}$ for $30-90 \mathrm{~min}$ with slight agitation. Beads were washed four times in $1 \times$ RIPA. After the final wash, Laemmli sample buffer was added to the samples. Next, proteins were fractionated by SDS-PAGE and transferred to polyvinylidene difluoride membranes (Immobilon-P, Millipore). The antibody used specifically to detect Rap1 was a monoclonal antibody directed against Rap1 (Transduction Laboratories). Immune complexes were detected by enhanced chemiluminescence (Amersham). All experiments shown here were performed at least three times with the same result to exclude donor-specific effects.

\section{Calcium measurements}

PRP was prepared as described above. ACD was added and platelets were incubated with $3 \mu \mathrm{M}$ Fura-2-AM for $45 \mathrm{~min}$ at $37^{\circ} \mathrm{C}$. Surplus Fura-2-AM and plasma were removed by gel filtration over a Sepharose 2B column equilibrated in HEPES/Tyrode buffer. Measurement of the cytosolic $\mathrm{Ca}^{2+}$ concentration was performed using a Hitachi F4500 fluorescence spectrophotometer by a dual wavelength program (excitation was measured at $340 \mathrm{~nm}$ and $380 \mathrm{~nm}$, emission at $510 \mathrm{~nm}$ ).

\section{Cell fractionation}

Samples of $5 \times 10^{8}$ platelets $/ \mathrm{ml}$ were lysed in cold $2 \times$ CSK buffer (100 mM Tris-HCl, $20 \mathrm{mM}$ EGTA, 2\% Triton X-100, $2 \mathrm{mM}$ sodium orthovanadate, $2 \mathrm{mM}$ PMSF, $2 \mu \mathrm{g} / \mathrm{ml}$ aprotinin, $2 \mu \mathrm{g} / \mathrm{ml}$ leupeptin) after stimulation. Lysis was for at least $10 \mathrm{~min}$ at $4^{\circ} \mathrm{C}$. Lysates were centrifuged at maximal speed in an Eppendorf centrifuge for $10 \mathrm{~min}$ at $4^{\circ} \mathrm{C}$. The pellet containing the actin cytoskeleton of the lysed platelets was washed once with $1 \times$ CSK buffer and centrifuged as before. Laemmli sample buffer was added to the pellet. Amounts of protein representing equal numbers of platelets were used for SDS-PAGE.

\section{Acknowledgements}

We thank Fred Wittinghofer for communicating the high affinity of RBD for Rap1 prior to publication, Marcel Spaargaren for the RBD construct and our colleagues for support, discussions and critically reading the manuscript. This work was supported by a grant provided by the Netherlands Heart Foundation (grant 94.136).

\section{References}

Altschuler,D.L., Peterson,S.N., Ostrowski,M.C. and Lapetina,E.G. (1995) Cyclic AMP-dependent activation of Rap1b. J. Cell Biol., 270, 10373-10376.
Ammit,A.J. and O'Neill,C. (1991) Rapid and selective measurement of platelet-activating factor using a quantitative bioassay of platelet aggregation. J. Pharmacol. Methods, 26, 7-21.

Authi,K.S., Bokkola,S., Patel,Y., Kakkar,V.V. and Munkonge,F. (1993) $\mathrm{Ca}^{2+}$ release from platelet intracellular stores by thapsigargin and 2,5di-( $t$-butyl)-1,4-benzohydroquinone: relationship to $\mathrm{Ca}^{2+}$ pools and relevance in platelet activation. Biochem. J., 294, 119-126.

Benton,A.M., Gerrard,J.M., Michiel,T. and Kindon,S.E. (1982) Are lysophosphatidic acids or phosphatic acids involved in stimulus activation coupling in platelets? Blood, 60, 642-649.

Burgering,B.M.T., Pronk,G.J., van Weeren,P.C., Chardin,P. and Bos,J.L. (1993) cAMP antagonizes p $21^{\text {ras }}$-directed activation of extracellular signal-regulated kinase 2 and phosphorylation of mSOS nucleotide exchange factor. $E M B O J ., 12,4211-4220$.

Calvete,J.J. (1994) Clues for understanding the structure and function of a prototypic human integrin: the platelet glycoprotein IIb/IIIa complex. Thromb. Haemostasis, 72, 1-15.

Campa,M.J., Chang,K.J., Molina y Vedia,L., Reep,B.R. and Lapetina,E.G. (1991) Inhibition of Ras-induced germinal vesicle breakdown in Xenopus oocytes by Rap-1B. Biochem. Biophys. Res. Commun., 174, $1-5$.

Cavallini,L. and Alexandre,A. (1994) Calcium efflux from platelets. Eur. J. Biochem., 222, 693-702.

Cavallini,L., Coassin,M. and Alexandre,A. (1995) Two classes of agonistsensitive $\mathrm{Ca}^{2+}$ stores in platelets, as identified by their differential sensitivity to 2,5-di-(tert-butyl)-1,4-benzohydroquinone and thapsigargin. Biochem. J., 310, 449-452.

Cook,S.J. and McCormick,F. (1993) Inhibition by cAMP of Rasdependent activation of Raf. Science, 262, 1069-1072.

Cook,S., Rubinfeld,B., Albert,I. and McCormick,F. (1993) RapV12 antagonizes Ras-dependent activation of ERK1 and ERK2 by LPA and EGF in Rat-1 fibroblasts. EMBO J., 12, 3475-3485.

Dash,D., Aepfelbacher,M. and Siess,W. (1995) Integrin $\alpha$ IIb $\beta 3$-mediated translocation of $\mathrm{CDC} 42 \mathrm{Hs}$ to the cytoskeleton in stimulated human platelets. J. Biol. Chem., 270, 17321-17326.

Doni,M.G., Cavallini,L. and Alexandre,A. (1994) $\mathrm{Ca}^{2+}$ influx in platelets: activation by thrombin and by the depletion of the stores. Effect of cyclic nucleotides. Biochem. J., 303, 599-605.

Fischer,T.H., Gatling,M.N., Lacal,J.-C. and White,G.C.,II (1990) Rap1B, a cAMP-dependent protein kinase substrate, associates with the platelet cytoskeleton. J. Biol. Chem., 265, 19405-19408.

Fischer,T.H., Gatling,M.N., McCormick,F., Duffy,C.M. and White, G.C.,II (1994) Incorporation of Rap1b into the platelet cytoskeleton is dependent on thrombin activation and extracellular calcium. J. Biol. Chem., 269, 17257-17261.

Fox,J.E.B. (1993) The platelet cytoskeleton. Thromb. Haemostasis, 70, 884-893.

Frech,M., John,J., Pizon,V., Chardin,P., Tavitian,A., Clark,R., McCormick,F. and Wittinghofer,A. (1990) Inhibition of GTPase activating protein stimulation of ras-p21 GTPase by the Krev-1 gene product. Science, 249, 169-171

Gabig,T.G., Crean,C.D., Mantel,P.L. and Rosli,R. (1995) Function of wild-type or mutant Rac2 and Rap1a GTPases in differentiated HL60 cell NADPH oxidase activation. Blood, 85, 804-811.

Grünberg,B., Kruse,H.-J., Negrescu,E.V. and Siess,W. (1995) Platelet Rap $1 \mathrm{~B}$ phosphorylation is a sensitive marker for the action of cyclic AMP- and cyclic GMP-increasing platelet inhibitors and vasodilators. J. Cardiovasc. Pharmacol., 25, 545-551.

Hartwig,J.H. (1992) Mechanisms of actin rearrangements mediating platelet activation. J. Cell Biol., 118, 1421-1442.

Hata,Y., Kikuchi,A., Sasaki,T., Schaber,M.D., Gibbs,J.B. and Takai,Y. (1990) Inhibition of the ras p21 GTPase-activating protein-stimulated GTPase activity of c-Ha-ras p21 by smg p21 having the same putative effector domain as ras p21s. J. Cell Biol., 265, 7104-7107.

Herrmann,C., Horn,G., Spaargaren,M. and Wittinghofer,A. (1996) Differential interaction of the Ras family GTP-binding proteins H-Ras, Rap1A, and R-Ras with the putative effector molecules Raf kinase and Ral-guanine nucleotide exchange factor. J. Biol. Chem., 271, 6794-6800.

Hynes,R.O. (1992) Integrins: versality, modulation, and signaling in cell adhesion. Cell, 69, 11-25.

Inazu,T., Taniguchi,T., Ohta,S., Miyabo,S. and Yamamura,H. (1991) The lectin wheat germ agglutinin induces rapid protein-tyrosine phosphorylation in human platelets. Biochem. Biophys. Res. Commun., 174, 1154-1158.

Kawata,M., Kikuchi,A., Hoshijima,M., Yamamoto,K., Hashimoto,E., Yamamura,H. and Takai,Y. (1989) Phosphorylation of smg p21, a ras 
p21-like GTP-binding protein, by cyclic AMP-dependent protein kinase in a cell-free system and in response to prostaglandin $E_{1}$ in intact human platelets. J. Biol. Chem., 264, 15688-15695.

Kroll,M.H. and Schafer,A.I. (1989) Biochemical mechanisms of platelet activation. Blood, 74, 1181-1195.

Lapetina,E.G., Lacal,J.C., Reep,B.R. and Molina y Vedia,L. (1989) A ras-related protein is phosphorylated and translocated by agonists that increase cAMP levels in human platelets. Proc. Natl Acad. Sci. USA, 86, 3131-3134

Nakamura,K., Kimura,M. and Aviv,A. (1995) Role of cyclic nucleotides in store-mediated external $\mathrm{Ca}^{2+}$ entry in human platelets. Biochem. J., 310, 263-269.

Nassar,N., Horn,G., Herrmann,C., Scherer,A., McCormick,F. and Wittinghofer,A. (1995) The $2.2 \AA$ crystal structure of the Ras-binding domain of the serine/threonine kinase c-Raf1 in complex with Rap1A and a GTP-analogue. Nature, 375, 554-560.

Noda,M. (1993) Structures and functions of the Krev-1 transformation suppressor gene and its relatives. Biochim. Biophys. Acta, 1155, 97-109.

Okamoto,Y., Ninomiya,N., Miwa,S. and Masaki,T. (1995) Capacitative $\mathrm{Ca}^{2+}$ entry in human platelets is resistant to nitric oxide. Biochem. Biophys. Res. Commun., 212, 90-96.

Polakis,P., Rubinfeld,B. and McCormick,F. (1992) Phosphorylation of rap1GAP in vivo and by cAMP-dependent kinase and the cell cycle p34 ${ }^{\text {cdc2 }}$ kinase in vitro. J. Biol. Chem., 267, 10780-10785.

Quinn,M., Parkos,C.A., Walker,L., Orkin,S.H., Dinauer,M.C. and Jesaitis,A.J. (1989) Association of a Ras-related protein with cytochrome $b$ of human neutrophils, Nature, 342, 198-200.

Rubinfeld,B., Crosier,W.J., Albert,I., Conroy,L., Clark,R., McCormick,F and Polakis,P. (1992) Localization of the rap1GAP catalytic domain and sites of phosphorylation by mutational analysis. Mol. Cell. Biol., 12, 4634-4642.

Shen,T.Y. and Winter,C.A. (1977) Chemical and biological studies on indomethacin, sulindac and their analogs. Adv. Drug Res., 12, 89-245.

Siess,W. (1989) Molecular mechanisms of platelet activation. Physiol. Rev., 69, 58-178.

Siess,W. and Grünberg,B. (1993) Phosphorylation of rap1B by protein kinase A is not involved in platelet inhibition by cyclic AMP. Cell Signal., 5, 209-214.

Siess,W. and Lapetina,E.G. (1989) Prostacyclin inhibits platelet aggregation induced by phorbol ester or a $\mathrm{Ca}^{2+}$ ionophore at steps distal to activation of protein kinase $\mathrm{C}$ and $\mathrm{Ca}^{2+}$-dependent protein kinases. Biochem. J., 258, 57-65.

Siess,W., Winegar,D.A. and Lapetina,E.G. (1990) Rap1-B is phosphorylated by protein kinase A in intact human platelets. Biochem. Biophys. Res. Commun., 170, 944-950.

Spaargaren,M. and Bischoff,J.R. (1994) Identification of the guanine nucleotide dissociation stimulator for $\mathrm{Ral}$ as a putative effector molecule of R-ras, H-ras, K-ras, and Rap. Proc. Natl Acad. Sci. USA, 91, 12609-12613.

Tamaoki,T. (1991) Use and specificity of staurosporine, UCN-01, and calphostin $\mathrm{C}$ as protein kinase inhibitors. Methods Enzymol., 201 340-347.

Torti,M. and Lapetina,E.G. (1992) Role of Rap1B and p2 $1^{\text {ras }}$ GTPaseactivating protein in the regulation of phospholipase C- $\gamma 1$ in human platelets. Proc. Natl Acad. Sci. USA, 89, 7796-7800.

Torti,M. and Lapetina,E.G. (1994) Structure and function of rap proteins in human platelets. Thromb. Haemostasis, 71, 533-543.

Toullec,D. et al. (1991) The bisindolylmaleimide GF $109203 \mathrm{X}$ is a potent and selective inhibitor of protein kinase C. J. Biol. Chem., 266, $15771-15781$.

Van Willigen,G., Hers,I., Corter,C. and Akkerman,J.-W.N. (1996) Exposure of ligand-binding sites on platelet integrin $\alpha \mathrm{II}_{3} / \beta_{3}$ by phosphorylation of the $\beta_{3}$ subunit. Biochem. J., 314, 769-779.

Watson,S.P., Poole,A. and Asselin,J. (1995) Ethylene glycol bis( $\beta$ aminoethyl ether)- $N^{\prime}, N^{\prime}, N^{\prime}, N^{\prime}$-tetraacetic acid (EGTA) and the tyrphostin ST271 inhibit phospholipase C in human platelets by preventing $\mathrm{Ca}^{2+}$ entry. Mol. Pharmacol., 47, 823-830.

Wittinghofer,A. and Herrmann,C. (1995) Ras-effector interactions, the problem of specificity. FEBS Lett., 369, 52-56.

Wu,J., Dent,P., Jelinek,T., Wolfman,A., Weber,M.J. and Sturgill,T.W. (1993) Inhibition of the EGF-activated Map kinase signal pathway by adenosine 3',5'-monophosphate. Science, 262, 1065-1069.

Yoshida,Y., Kawata,M., Miura,Y., Musha,T., Sasaki,T., Kikuchi,A. and Takai,Y. (1992) Microinjection of smg/rap1/Krev-1 p21 into Swis 3T3 cells induces DNA synthesis and morphological changes. Mol. Cell. Biol., 12, 3407-3414.
Zhang,Z., Vuori,K., Wang,H.-G., Reed,J.C. and Ruoslahti,E. (1996) Integrin activation by R-ras. Cell, 85, 61-69.

Received on September 13, 1996 